\title{
Media Reviews
}

The Eugenics Society digital archive, part of 'Codebreakers: makers of modern genetics', The Wellcome Library, London.

With relatively little fanfare, the Wellcome Library in London has digitised a number of its significant collections relating to the history of genetics. For historians of science, this is a tremendous resource that is currently matched by only a few other libraries or archives.

Announced on the Wellcome Library blog in early January 2013, the new online resource 'Codebreakers: makers of modern genetics' includes 20 archival collections pertaining to many of the most significant heredity and population researchers of the twentieth and twenty-first centuries, including J.B.S. Haldane, Lionel Penrose, James Renwick and Rosalind Franklin. A number of collections, including the Franklin papers, have been contributed by outside archives (in the case of the Franklin papers, Churchill Archives Centre, Cambridge). Online access to the collections is free, with papers less than a century old requiring the creation of a library username and password to view.

For historians of eugenics, two digitised collections stand out for their clear significance. The first of these is the Eugenics Society archive itself. Founded in 1907 by associates of Francis Galton, the Eugenics Society (initially called the Eugenics Education Society) was Britain's most significant eugenics lobbying group. With a mixed membership consisting of medical practitioners, scientific researchers and interested members of the public, the Society's leadership spent many of the years before the Second World War encouraging research into human heredity and exploring the possibility of passing eugenic legislation in Britain at a time when the American and, after 1933, the German eugenics movements had outstripped them by successfully advocating the passage of aggressive sterilisation laws.

The Eugenics Society archive has long been a critical resource for historians of the biology and hereditary theory of the twentieth and twenty-first centuries. Its extensive correspondence sections contain valuable collections of letters from many leading scientific figures of the day, along with a sizable collection of correspondence from the often-eccentric fringes of the Society's membership. Now freely available online, it is all but certain that these papers will be even more widely consulted in the years to come.

The second collection of particular interest to historians of eugenics, along with a number of other scientific and medical disciplines, are the papers of Carlos Paton Blacker, frequently referred to as C.P. in documents and 'Pip' by his friends. Blacker was the Eugenics Society's head for much of the interwar period, arguably saving it from irrelevance and schism at a time when it was increasingly being torn in different directions in the early 1930s. Blacker was a psychiatrist by training and profession, and consequently many of his papers relate to his professional interests and activities beyond eugenics. He was also a close associate and friend of Julian Huxley, among other leading figures of the period. What is also evident from examining the catalogue of Blacker's papers is the sheer extent of his involvement with virtually every population-related group and movement of his time, ranging from the birth control movement to demography and population science. The Blacker papers have historically featured much less frequently in eugenics scholarship 
than the Eugenics Society papers themselves despite their obvious relevance, and it may be hoped that with their digitisation scholars will utilise them more frequently and fully.

There is already much scholarly literature discussing the impact of archive digitisation on historical research and there is little need to rehash the extensive existing arguments on the subject. However, in the case of these collections it is instructive to recall how rapidly access to their contents has increased. As Pauline Mazumdar recounted in the preface of her groundbreaking 1992 book Eugenics, Human Genetics and Human Failings, before 1989 the Eugenics Society's papers were still housed in the library of its thenheadquarters at 69 Eccleston Square, London. Mazumdar was granted access to the papers by the Society's Secretary, noting that the documents were 'not public property in any way' when her research commenced in 1976. The archive was subsequently transferred to the Wellcome Library, but the conditions of access required researchers to contact the Galton Institute (as the Eugenics Society was later renamed) for formal permission to utilise the collection. In addition, the collection was generally produced for readers to examine on microfilm, with the original documents rarely made available. Though still requiring the creation of a free Wellcome Library account to access many of the documents, it is clearly significant that any researcher may now access these documents at any time.

Further, a preliminary examination suggests that the collection's digitisation is fairly comprehensive. Researching over the course of several days in September 2013, I never encountered a problem gaining access to the document I was seeking through the Wellcome's online interface. Notes from past research conducted in the library itself suggest that the folders I viewed were complete digital versions of what I had seen previously, with no documents seemingly omitted.

There are certainly many advantages to digital collections. One of the primary benefits is the ability to search the entire catalog by keyword or name and then instantly access the documents matching the query. The Wellcome's interface for viewing documents is reasonably intuitive and even allows users to download documents for future research use. Anyone who has consulted the Eugenics Society collection in the reading room will remember the vagaries of using the microfilm, including the inevitable focus knob adjustments needed to clear up the image and, occasionally, the need to squint at the screen until century-old handwriting could be discerned. In the course of my PhD research in the late 2000s there were many days I began my journey home walking down Euston Road with a microfilm-induced headache. With the papers now digitised, a full-colour version of the original can be zoomed to any level on a computer screen, making documents significantly easier to read and even revealing details that were previously imperceptible.

These advantages are clearly significant, and it seems likely that there will be a significant reevaluation of past scholarship in light of the remarkable new accessibility of these documents. Researchers examining secondary sources now have the ability to immediately consult the primary source being referenced and make their own determinations about its context and implications, which may well lead to an expansion of revisionist scholarship.

These advantages aside, the experience of visiting the Wellcome Library itself will clearly not become a thing of the past for many if not most scholars. Many researchers feel a certain je ne sais quoi when they work in the archives that cannot be reproduced with a computer screen: it is in part a feeling of adventure, as if one is about to become the first historian to ever set eyes on the next document in the folder or on the microfilm. This is, of course, an illusion in most cases, but it is one reason digitisation will never replace the archive reading room for many researchers. The Wellcome Library has clearly done 
the scholarly community a great service by making these important collections available online. However, it seems likely that the Rare Materials Reading Room in the library on Euston Road will remain busy for the foreseeable future.

Bradley W. Hart

California State University, USA

doi:10.1017/mdh.2013.84

\section{The Hunterian Museum at the Royal College of Surgeons, London, England}

A visitor to the Hunterian Museum could easily be excused for thinking that they had wandered into the home of some crazed collector fascinated by the rare and the exotic, the obscure and the bizarre. Indeed, this perception would not be so far from the truth. Housed in the Royal College of Surgeons in London, the museum has assumed a variety of forms and functions over its long history (the museum celebrated its bicentennial in 2013). The museum helped the College secure its Royal Charter in 1800, has served as a vital site for surgical teaching and anatomical research, and for a long time shaped the public image of anatomy, physiology and surgery. Today, the museum offers visitors an opportunity to explore the life and work of John Hunter (1728-93), the renowned eighteenth-century surgeon, anatomist, naturalist and teacher responsible for assembling the museum's core collection.

The heart of the museum, both physically and spiritually, is the Crystal Gallery, a magnificent wunderkammer containing a dizzying array of anatomical preparations and specimens collected from every corner of the natural world. Originally displayed in the museum that Hunter built between his home in Leicester Square and his dissecting rooms in Castle Street, the collection was purchased by the British government in 1799 and installed in the College of Surgeons in 1813. Following the museum's most recent refurbishment in 2005, the specimens (mostly preserved in jars) are arranged according to Hunter's original classification scheme: anatomical specimens (human, plant, and animal) are organised by bodily process (digestion, reproduction, generation, etc.), while pathological preparations are arranged to illustrate both the general principles of disease and specific morbid conditions. These strangely beautiful, or at least beautifully strange artefacts range from enormous animal skulls to the dissected carcasses of reptiles, birds and rodents; from strange eggs and organs to preserved human limbs, tissues and even the seven-foot-seven skeleton of Charles Byrne, the so-called 'Irish Giant'. Those who are weak-of-stomach or faint-of-heart should be wary; certain items, such as the severed face of a child who suffered from smallpox, can be both jarring and haunting.

The exhibits encircling the Crystal Gallery provide historical context for this large and often perplexing collection of objects. Displays filled with specimens, instruments and images explain various scientific and social aspects of anatomical dissection in the eighteenth century, such as its reliance on the bodies of executed criminals as well as corpses snatched from graves by 'resurrection men'. Most of the attention is given to Hunter's life and work, including his role preparing specimens for his older brother William's famous anatomy lectures and the growth of his own fame as a surgeon and experimenter. Some of the most interesting objects in the collection are those that testify to Hunter's skill at anatomical preparation or illustrate his contributions to dental and 